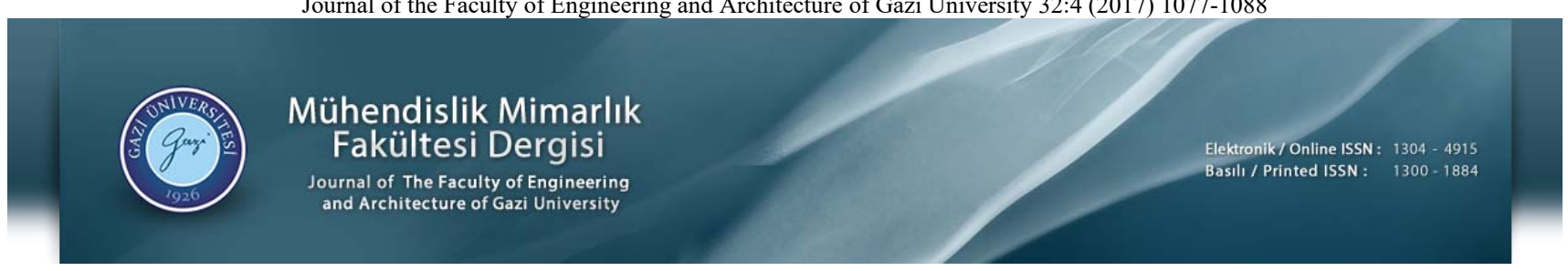

\title{
SAE 1030 çelik dövme malzemenin tornalama işleminde kesme parametrelerinin ve takım aşınmasının akustik olarak incelenmesi
}

\author{
Kemal Yaman ${ }^{1 *(D)}$, Mustafa Başaltın¹,2 \\ ${ }^{1}$ Türkiye Bilimsel ve Teknik Araştırma Kurumu Savunma Araştırma Geliştirme Enstitüsü (TÜBİTAK SAGE), 06261, Ankara, Türkiye \\ ${ }^{2}$ Gazi Üniversitesi, Fen Bilimleri Enstitüsü, Teknik Eğitim Fakültesi Makine Eğitimi Bölümü, 06560, Ankara, Türkiye
}

\section{Ö N E C I K A N L A R}

- Ses basınç seviyesi yöntemiyle takım aşınmasının kontrol edilmesi

- Kesme parametrelerinin takım aşınmasına etkileri

- Yüzey pürüzlülüğüyle akustik yayılım arasındaki ilişki

Makale Bilgileri

Geliș: 01.06.2016

Kabul: 31.07 .2017

DOI:

10.17341/gazimmfd.369394

Anahtar Kelimeler:

Akustik emisyon,

takım aşınması,

kesme parametreleri,

ses analizi,

yüzey pürüzlülüğü

\section{ÖZET}

Bu çalışmada, takım aşınması ve kesme parametrelerinin torna tezgâhında işleme esnasında yayılan ses sinyalleriyle (AE) olan ilişsisi incelenmiştir. SAE 1030 çelik dövme iş parçası, kesme hızı ve ilerleme hızı olmak üzere, en uygun kesme parametrelerini belirleyebilmek için işlemeye maruz bırakılmıştır. Deneyler, CNC tipi bir torna tezgâhında, 1,5 mm sabit kesme derinliğinde, 130,140, $150 \mathrm{~m} \backslash \mathrm{dk}$ kesme hızları ve 0,15, 0,20 ve $0,30 \mathrm{~mm} / \mathrm{dev}$ ilerleme hızlarında işlenerek gerçekleştirilmiştir. Deneyler sonucunda sırasıyla en uygun kesme ve ilerleme hızı $140 \mathrm{~m} / \mathrm{dk}$ ve $0,20 \mathrm{~mm} / \mathrm{dev}$ olarak tespit edilmiștir. Tespit edilen bu işleme parametreleri kullanılarak 5, 10, 15 ve 20'şer dakika ayrı sürelerde, iki farklı karbür kesici uç (IC8250, IC9250), işleme yapılarak AE cevapları analiz edilmiştir. Sonuçlar yanak aşınması (VB) arttıkça AE verilerinin de arttığını göstermiştir. Nihayetinde, takım aşınmasıyla $\mathrm{AE}$ arasında güçlü bir ilişki olduğu ve takım aşınmasının AE sinyalleriyle izlenebileceği görülmüştür. Takım aşınması modelleri son kısımda verilmiştir.

\section{Investigations on the cutting parameters and the tool wear of SAE 1030 forged steel material by acoustic emission in turning operation}

\section{H I G H L I G H T S}

- Tool wear monitoring by using sound pressure level method

- The effect of cutting parameters on tool wear

- The relationship between surface roughness and acoustic emission

Article Info

Received: 01.06.2016

Accepted: 31.07 .2017

DOI:

10.17341/gazimmfd.369394

Keywords:

Acoustic emission, tool wear, cutting parameters, sound analysis,

surface roghness

\begin{abstract}
In this work, the relation of the tool wear and machining parameters with the Acoustic Emission (AE) signals are investigated. SAE 1030 forged steel workpart is subjected to the machining to determine the effective machining parameters namely, cutting speed and feed rate. The experiments are performed for $1.5 \mathrm{~mm}$ constant depth of cut in a CNC type turning machine by using $130,140,150 \mathrm{~m} / \mathrm{min}$ cutting speed and 0.15 , $0.20,0.30 \mathrm{~mm} / \mathrm{rev}$ feed rate. The suitable cutting speed and feed rate is determined as $140 \mathrm{~m} / \mathrm{min}$ and 0,20 $\mathrm{mm} / \mathrm{rev}$ respectively. The AE responds of the tool wear are analyzed for machining time of 5, 10, 15 and 20 minute separately for two different type carbide tool inserts (IC8250, IC9250) by using the decided cutting parameters. The results show that, the AE values increase with increasing the flank wear (VB). It is observed finally that the relationship between the tool wear and $\mathrm{AE}$ is strong and the tool wear can be monitored by using the AE signals. The wear models of the cutting tools have been derived in the final section.
\end{abstract}




\section{GIRIŞS (INTRODUCTION)}

Talaş kaldırma işlemlerinde temel amaç, kesici takımın yüksek performansla maksimum takım ömrü boyunca talaş kaldırabilmesidir [1]. Kesici takımın kullanılamaz duruma gelmeden önce kontrollü bir şekilde devre dişı bırakılması işlemenin sağlı̆̆ açısından son derece önemlidir. Takım aşınmasının ve kırılmanın gerçek zamanlı olarak izlenmesi için geliştirilen tekniklerin çoğu pratik kullanıma uygun değildir. Prensip olarak ölçüm sırasında talaş kaldırma işlemi durdurulmamalıdır. Kesme kuvvetleri değişimine bağlı takım durumu izleme yöntemi çalışma ortamından olumsuz etkilenmekte ve kesme işlemi sırasında gerçek zamanlı ölçüm istenildiği gibi yapılamamaktadır [1].

İyi bir takım aşınması-yüzey pürüzlülüğü izleme sistemi kurabilmek için işlemenin arka planına bakmak gerekmektedir. Taşliyan vd. [2], kesme parametrelerinden kesme hızı, ilerleme hızı ve kesme derinliğinin kesme kuvvetleri üzerindeki etkilerini araştırmışlardır. Bu amaçla nikel esaslı Inconel-718 süper alaşımı; 1,20 mm uç radyüsüne sahip seramik kesici takımla bilgisayarlı sayısal denetimli (CNC) torna tezgâhında, soğutma sıvısı kullanılmadan işlenmiştir. Kesme parametreleri olarak beş farklı kesme hızı $(225,300,350,400,500 \mathrm{~m} /$ dak $)$ ve beş farklı ilerleme hızı $(0,05,0,075,0,1,0,125,0,15 \mathrm{~mm} / \mathrm{dev})$ ile iki farklı kesme derinliği (1 $\mathrm{mm}, 2 \mathrm{~mm})$ değerleri kullanılmıştır. Yapılan deneylerde kesme hızı, ilerleme hızı ve kesme derinliğine bağlı olarak en düşük kesme kuvveti ( $500 \mathrm{~m} /$ dak kesme hızı $0,05 \mathrm{~mm} / \mathrm{dev}$ ilerleme hızı ve $1 \mathrm{~mm}$ kesme derinliğinde) $192 \mathrm{~N}$ ve en yüksek kesme kuvveti ise ( $225 \mathrm{~m} /$ dak kesme hız $0,15 \mathrm{~mm} / \mathrm{dev}$ ilerleme hız ve $2 \mathrm{~mm}$ kesme derinliğinde) $780 \mathrm{~N}$ olarak elde edilmiştir. Kesme kuvvetlerindeki bu radikal artışın kesme şartlarını zorlaştırdığını ve bunun sonucu olarak takımın aşındı ğını ve çıkan iş parçası yüzey kalitesinin düştüğünü belirtmişlerdir. Kesme parametrelerinin, yüzey pürüzlülüğüne ve takım aşınmasına etkileri konusunda benzer sonuçlar Kaçal vd. [3] ve Altın [4] tarafindan yapılan çalışmalarda da görülmektedir. Tornalama işleminde olduğu gibi frezeleme işlemi göz önüne alındığında kesme derinliği ve ilerleme hızı arttıkça takım aşınması ve yüzey pürüzlülüğünün arttı̆̆1 görülmektedir [5, 6]. Li [7], tornalama sırasında takım aşınmasını takip edebilmek için akustik emisyon (AE) yönteminin kullanımını çeşitli metotlar kullanarak araştırmıştır. Araştırmalar, AE metodunun takım aşınmasını takip etmek için etkili bir yöntem olduğunu göstermiştir. Elde edilen AE sinyalleri, zaman serileri analizi, FFT ve wavelet transform analizleri gibi çeşitli metotlarla analiz edilmiştir. Takım aşınması şartlarının önceden tahmini konusunda bulanık sınıflandırma, yapay sinir ağları ve veri birleştirme gibi birçok yöntem kullanılmıştır.

$\mathrm{Bu}$ çalışmalar sonucunda, $\mathrm{AE}$ sinyallerinin kesme parametreleriyle doğrudan ilişkili olduğunu ve zeki bir takım aşınması/kırılması izleme sistemi için bu etkinin minimize edilmesi gerektiği ifade edilmiştir. Bu esasa göre, sisteme farklı sensörler entegre edilerek, sinyal işleme ve özellik çıkarma işlemleriyle çok daha etkili bir izleme sistemi kurulabileceği belirtilmiştir. Choi vd. [8], tornalamada gerçek zamanlı bir takım kırılması sensörü tasarlamışlardır. Tasarladıkları bu sensör, hem akustik yayılma verilerini toplayan bir AE sensörü hem de kuvvet verilerini ölçen bir piyozoelektrik yük sensöründen oluşmaktadır. İki set halinde tungsten karpit kullanarak gerçekleştirilen deneylerde, takım ömrünü tanımlamak için birinci deney setinde iş parçası pirinçle kaplanırken, ikinci deney setinde ise kırılmayı hızlandırmak için iş parçasına kanal (slot) delik açılmıştır. Kaydedilmiş veriler takım kırılmasını modellemek için hazırlanan bir algoritmayla analiz edilmiştir. AE sinyalleri, hassas veri alması gereken noktada yük sensörünü tetikleyerek veri almasını sağlar. Yük verilerinde ani düşüşün olduğu noktada sistem takımın kırıldığına dair uyarı sinyali üreterek işleme operasyonunu durdurur.

Deiab vd. [9], takım aşınmasının en önemli sebeplerinden kesme hızı, ilerleme hızı ve kesme derinliği olan üç ana işleme parametresini yapay sinir ağları kullanarak ses analizleriyle incelemişlerdir. Deneylerde teğetsel, eksenel ve radyal olmak üzere üç yönde oluşan kuvvetleri ölçmek için kesici takım üzerine monte edilmiş dinamometre kullanılmıştır. Kesme hızı 110 m/dk'dan 10'ar artışla 5 farklı hız seçilmiş $0,15-0,20$ ve 0,30 olmak üzere üç farklı ilerleme değeri ve $1 \mathrm{~mm}$ kesme derinliği seçilmiştir. Polinomik sınıflandırma ile elde edilmiş takım aşınması süresiyle yapay sinir ağıyla (ANN) elde edilmiş aşınma süresi karşılaştırılmıştır. Elde edilen tahmin sonuçlarıyla deneysel ölçümlerin tutarlı olduğu görülmüştür. Bhuiyan vd. [10] yaptıkarı deneylerle AE ve titreşim imzasının takım aşınmasına ve yüzey pürüzlülüğüne farklı cevaplar verdiğini göstermişlerdir. AE sinyallerinin takım aşınma gelişmesine, titreşim sinyallerinin ise yüzey pürüzlülüğüne daha belirgin cevap verdiğini görmüşlerdir. Titreşim genliğinin $x, y$ ve $z$ bileşenlerinin ilerleme hızı $(f)$, talaş derinliği $(a)$ ve kesme hızı $(V)$ arttıkça arttığını göstermişlerdir [11]. Farklı takım aşınması aşamalarında ve farklı kesme parametrelerinde AE ve tireşim frekans değerleri dalgalanma göstermiş olsa da, titreşim ferakans bandının 40-98 Hz ve AE frekans bandının da $51-620 \mathrm{kHz}$ aralığında değiştiği gözlemlenmiştir.

Downey vd. [12], HSS kesiciyle buhar çöktürmeli (PVD) Titanyum karbon-nitrit (TiCN) takma ucun işleme hassasiyetini, takım aşınma performansını ve elde edilen yüzey pürüzlülüğünü $\mathrm{AE}$ metoduyla deneysel olarak karşılaştırmışlardır. İşlemelerde numuneler $130 \mathrm{dev} / \mathrm{dk}$ işleme hızı, $120 \mathrm{~m} / \mathrm{dk}$ ilerleme ve $0,20 \mathrm{~mm}$ kesme derinliğ $\mathrm{i}$ parametrelerinde soğutma sıvısı kullanılarak farklı sürelerde tornalanmıştır. İşleme süresi bakımından temel olarak 3 farklı faza ayırarak elde edilen aşınma değerleri ve bunlara karşılık gelen sesler bir mikrofon aracılığıyla bilgisayar ortamına aktarılmıştır. Zamanla takım aşındıkça yayılan sesin de farklılaştığı ve her aşınma fazı için aşınmayı karakterize eden bir ses imzasının oluştuğunu rapor etmişlerdir. Bhuiyan vd. [13] bu çalışmalarında ise, 130-190 $\mathrm{m} /$ dak kesme hız1, 0,28-0,50 $\mathrm{mm} / \mathrm{dev}$ ilerleme ve $1,20 \mathrm{~mm}$ 
kesme derinliği değerleri kullanarak takım aşınmasını, talaş oluşum sırasında elde ettikleri frekansları diğer gürültü frekanslarından ayırarak analiz etmişlerdir. Kaba AE sinyalleri ve kareler ortalamasının karekökü (RMS), kesme hızı, ilerleme hızı ve kesme derinliği arttıkça takım aşınmasında ve iş parçası plastik deformasyonunda artışlar olduğunu göstermiştir. Öteyandan, yüksek işleme ve ilerleme hızlarında bile talaş kırmayla (chip breakage) daha düşük takım aşınması görülmüş, yapılan aşınma ölçümleriyle de bu sonuçlar doğrulanmıştır. Bhuiyan vd. [14] bir başka çalışmada ise taşlama operasyonunu $\mathrm{AE}$ yöntemiyle izlemişlerdir.AE sinyallerinin takım aşınmasıyla arttığını rapor etmişlerdir.Maia vd. [15], AE esasına dayanan yeni bir metodla takım aşınma mekanizması ve takım ömrü belirleme üzerine çalışmışlardır. Tornalama işlemi esnasında elde edilen AE sinyallerinin aşınma mekanizmasıyla yakın ilişkili olduğu görülmüştür. Çalışmlarda, takım ömrü sonunda en büyük yanak aşınmasına ulaşıldığında, ses sinyali ortalama güç tayf yoğunluğunun (PSD) genlik artışına sebep olduğu tespit edilmiştir. AE tekniği ile takım kırılmasının (tool failure) önceden kestirimi ve tespiti üzerine yeni bir metodun geliştirildiği bir başka çalışmada [16] titanyum karbür (TiC) takviyeli $\mathrm{Al}_{2} \mathrm{O}_{3}$ seramik takma uç kullanarak, 62 HRC sertlikte 100Cr6 Yatak çeliğini, 0,0750,25 mm kesme derinliği aralığında, 25-250 m/dak kesme hızı aralığında, soğutma sıvısı kullanmadan (hard turning) işlenmiştir. Bu yeni metotta iki farklı AE sensör kullanılarak $\mathrm{AE}_{\mathrm{rms}}$ (kareler ortalamasının karekökü), $\mathrm{AE}_{\text {strength }}$ (dayanım) ve $A E$ absolute energy (mutlak enerji) açılarından izlenmişlerdir. Oluşan talaş şekillerine karşıllık gelen kaba AE sinyalleri karşılaştırılarak kesme karakteristikleri çıkarılmıştır. AE tekniğinin takım aşınmasını izlemede çok hassas bir yöntem olduğunu fakat takım aşınmasının geçiş fazlarını yakalamada yetersiz olduğunu açıklamışlardır. Kaba AE sinyallerinin oluşan talaşın karakterini yansıttığını göstermişlerdir.

$\mathrm{Bu}$ makalede ise, SAE 1030 dövme çelik malzemenin en uygun işleme parametreleri altında, torna tezgâhında işleme sırasında çevreye yayılan AE sinyallerini izleyerek, takım aşınması ve iş parçası yüzey pürüzlülüğü ilişkisi incelenmiştir. Metal işleme olayının, işleme esnasında çevreye yaydığ 1 seslerin analiziyle karakterize edilmesi ve buradan hareketle takım aşınması ve takım ömrünün önceden tahmini amaçlanmıştır.

\section{DENEYSEL ÇALIŞMALAR (EXPERIMENTAL STUDIES)}

En uygun kesme parametrelerini torna tezgâhında işleme esnasındaki sese dayalı olarak tespit etmek için SAE 1030 dövme çelik malzemeden üretilen numuneler CNC tipi torna tezgâhında işlenmiştir. $\mathrm{Bu}$ işlemelerde 2 tip sert maden uç kullanılarak 10'ar dakika, 1,50 mm sabit talaş derinliği verilerek $27 \mathrm{~mm}$ çapında ve $175 \mathrm{~mm}$ boyunda silindirik numuneler 2 paso tornalanmıştır. Kesme hızları $130 \mathrm{~m} / \mathrm{dk}$, $140 \mathrm{~m} / \mathrm{dk}$ ve $150 \mathrm{~m} / \mathrm{dk}$ ilerleme hizları $0,15 \mathrm{~mm} / \mathrm{dev}, 0,20$ $\mathrm{mm} / \mathrm{dev}$ ve $0,30 \mathrm{~mm} / \mathrm{dev}$ seçilmiştir. İşleme esnasında mikrofon yardımıyla işleme sesleri bilgisayar ortamına kaydedilmiştir. Bu parametrelerde işlemeler tamamlandıktan sonra en uygun işleme parametresini bulabilmek için çıkan seslerin basınç düzeyleri ve yüzey kalitesi incelenmiştir. Bulunan en uygun işleme parametresi ile deney numuneleri 2 tip kesici uçla sabit ilerleme ve kesme hızında sırasıyla 5, 10,15 ve $20 \mathrm{dk}$ sürelerle işlenmiştir. Ayrı zaman aralıklarında elde edilen sesler mikrofon aracılığı ile yine bilgisayar ortamına aktarılmıştır. $\mathrm{Bu}$ işlemlerle, kesici uçların tezgâhtan çıkan sese bağlı olarak hangi zaman aralıklarında ne miktarda aşındığını görmek amaçlanmıştır.

İşleme deneyleri farklı kesici geometrisine sahip kesici takımlar kullanılarak TS 10329 standardı [17] göz önüne alınarak Goodway GA-2800L bilgisayar sayisal denetimli (CNC) bir tornalama merkezinde gerçekleştirilmiştir. Gerçekleştirilen çalışmalarda deney numunesi olarak Ø26×220 mm boyutlarında silindirik SAE 1030 dövme çelik parça kullanılmıştır. Gazi Üniversitesi Metalurji ve Malzeme Mühendisliği malzeme karakterizasyon labaratuvarında yapılan malzeme analizleri sonucunda elde edilen deney numunesi kimyasal bileşimi Tablo 1'de verilmiştir. Yapılan çekme testine göre deney numunesi ortalama \%37,97 uzama ve çekme kuvveti (maximum tensile load) 72668 Newton olarak tespit edilmiştir.

Deney malzemesi TS 10329 standardı göz önünde bulundurularak boy/çap oranı 10/1'den küçük olacak şekilde hazırlanmıştır [17]. Numune, ayna ile punta arasında Şekil 1 'de gösterildiği gibi işlemeye uygun olacak biçimde numunenin ucuna punta deliği açılarak her iki uçtan bağlanmiştır.

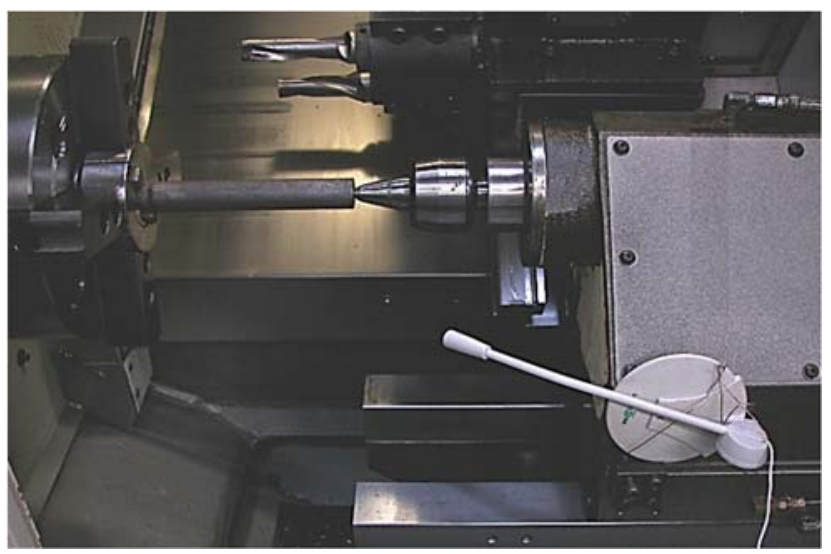

Şekil 1. Deney düzeneği (Test setup)

Tablo 1. Deney numunesi SAE 1030 çeliğinin kimyasal kompozisyonu (Chemical composition of SAE 1030 test sample)

\begin{tabular}{lllllllll}
\hline \multirow{2}{*}{ Kimyasal Bileşimi } & $\mathrm{C}$ & $\mathrm{Cr}$ & $\mathrm{Mn}$ & $\mathrm{Mo}$ & $\mathrm{Ni}$ & $\mathrm{Cu}$ & $\mathrm{S}$ & $\mathrm{P}$ \\
\cline { 2 - 9 } & 0,30 & 0,07 & 0,68 & 5,00 & 0,09 & 0,29 & 0,028 & 0,012 \\
\hline
\end{tabular}


Deneylerde IC8250 ve IC9250 (ISCAR ${ }^{\circledR}$ ) tip olmak üzere iki farklı karbür takma uç kullanılmıştır. Kesiciler TiAlN ile PVD (fiziksel buhar çökertmesi) yöntemiyle kaplanmışlardır. Kater olarak DDJNR 2525 M-15 kod numaralı takım tutucu kullanılmıştır. İşlemelerde numune çapları standart mikrometre kullanılarak ölçülmüştür. Parça programı ölçülen değerler göz önüne alınarak hazırlanmıştır. İşlenmiş numunelerin yüzey pürüzlülüğü, hassasiyeti 0,001 mm olan Mitutoyo SJ-310 tipi yüzey pürüzlülük ölçüm cihazıyla ölçülmüştür. Belirlenen kesme parametrelerinde deney numunelerinden talaş kaldırdıktan sonra kesici takımlar üzerinde meydana gelen yığma kenar ve yanak aşınmaları SEM fotoğrafları çekilerek görüntülenmiştir. Takım üzerinde aynı bölgeden alınan görüntüler incelenerek aşınma büyüklükleri kıyaslanmıştır. İşleme sırasında kaydedilen ses sinyallerinin ses basınç seviyeleri Matlab ${ }^{\circledR}$ programı kullanılarak hesaplanmıştır. Ses basınç seviyeleri ölçülürken deneylerin yapıldığı imalathanedeki diğer tezgâhlar kapatılarak sessiz bir ortam sağlanmıştır. İlk olarak makine boşta çalıştırılmış, daha sonra her kesme parametresi için ayrı ayrı sesler kaydedilmiştir. Sağlıklı ölçüm yapmak için Matlab programında tezgâhın talaş kaldırırken çıkan sesten tezgâhın boşta çalışma sesi çıkarılmış ve işleme ses basınç seviyeleri hesaplanmıştır. Mikrofon aracılığı ile kayıt edilen sesler Cool Edit Pro $1.2^{\circledR}$ programı kullanılarak bilgisayar ortamına uygun olarak sayısallaştırılmıştır. Bu program kullanılarak işleme seslerinin daha iyi anlaşılabilmesi ve karşılaştırılabilmesi için numune parçalarının işlenmesinde ilk 80 mm'lik tornalama boyundaki sesler esas alınmıştır. Deneylerde, ilk olarak iki farklı kesici takım malzemesinin katalog değerlerinden alınan verilerden $130 \mathrm{~m} / \mathrm{dk}, 140 \mathrm{~m} / \mathrm{dk}$ ve $150 \mathrm{~m} / \mathrm{dk}$ olmak üzere 3 farklı kesme hızı denenmiştir. Buna karşılık bu kesme hılarının her biri için ayrı ayrı 0,15 mm/dev, 0,2 $\mathrm{mm} / \mathrm{dev}$ ve $0,3 \mathrm{~mm} / \mathrm{dev}$ olmak üzere 3 farklı ilerleme hızı kullanılmıştır. En uygun işleme parametreleri olarak 140 $\mathrm{m} / \mathrm{dk}$ kesme hızı ve $0,2 \mathrm{~mm} / \mathrm{dev}$ ilerleme hızı belirlenmiştir Belirlenen sabit kesme hızı ve ilerlemede deney numunesi $t_{1}=5 \mathrm{dk}, t_{2}=10 \mathrm{dk}, t_{3}=15 \mathrm{dk}, t_{4}=20 \mathrm{dk}$ işleme sürelerinde işlenmiştir. Deney numunelerinin her bir kesme şartı için yeni bir uç kullanılmıştır. Çalışmalarda ses kaydının daha iyi yapılabilmesi için soğutma sıvısı kullanılmamıştır.

\section{SONUÇLAR VE TARTIŞMALAR (RESULTS AND DISCUSSIONS)}

\subsection{SAE 1030 Dövme Çeliğin İşlenmesinde Oluşan Yanak Aşınması Ile Kesme Parametreleri Arasındaki İlişki (The relation Between the Flank wear and the Cutting Parameters of SAE 1030 Forged Steel)}

Hazırlanan deney numuneleri CNC torna tezgâhında sabit $1.5 \mathrm{~mm}$ talaş derinliğii, $V_{1}=130 \mathrm{~m} / \mathrm{dk}, V_{2}=140 \mathrm{~m} / \mathrm{dk}, V_{3}=150$ $\mathrm{m} / \mathrm{dk}$ kesme hizında $f_{1}=0,15 \mathrm{~mm} / \mathrm{dev}, f_{2}=0,20 \mathrm{~mm} / \mathrm{dev}, f_{3}=$ $0,30 \mathrm{~mm} / \mathrm{dev}$ olmak üzere 3 farklı ilerleme hızında kesici takım üzerinde meydana gelen VB yanak aşınması miktarı karşılaştırılmıştır. Buna göre kesme hızının artması ile VB yanak aşınması değerinin azaldığı tespit edilmiştir. İlerleme hızı $0,15 \mathrm{~mm} / \mathrm{dev}^{\prime}$ den $0,20 \mathrm{~mm} / \mathrm{dev}$ 'e yükseltildiğinde yanak aşınması azalırken $0,30 \mathrm{~mm} / \mathrm{dev}$ 'e çıkarıldığında VB değerinde artış gözlemlenmiştir. $\mathrm{Bu}$ işlemler göz önünde bulundurularak kesme hızı artığında yanak aşınmasının azaldığı dolaylı olarak takım ömrünün artığ1 sonucuna ulaşılabilir. $140 \mathrm{~m} / \mathrm{dk}$ kesme hızında ve $0,20 \mathrm{~mm} / \mathrm{dev}$ ilerleme hızında en az yanak aşınması olduğu gözlemlenmiştir. Tablo 2'de farklı kesme parametrelerinden meydana gelen yanak aşınma değerleri sayısal olarak ve bu değerlerin grafiksel gösterimi ise Şekil 2a'da (IC8250 tip Karbür takma uc için) ve Şekil 2b'de (IC9250 tip Karbür takma uç için) gösterilmiştir.

Tablo 2. İki farklı tip uç için ölçülen yanak aşınması değerleri

(The flank wears measured for two different type insert)

\begin{tabular}{lllll}
\hline Kesici Uç & İlerleme Hız1 & \multicolumn{3}{l}{ Kesme Hız1 $[\mathrm{m} / \mathrm{dk}]$} \\
\cline { 3 - 5 } Tipi & {$[\mathrm{mm} / \mathrm{dev}[\mathrm{mm}]$} \\
\hline \multirow{2}{*}{ IC8250 } & 0,15 & 0,060 & 0,055 & 0,050 \\
& 0,20 & 0,055 & 0,045 & 0,040 \\
& 0,30 & 0,060 & 0,050 & 0,045 \\
IC9250 & 0,15 & 0,070 & 0,065 & 0,045 \\
& 0,20 & 0,065 & 0,060 & 0,055 \\
& 0,30 & 0,075 & 0,070 & 0,060 \\
\hline
\end{tabular}

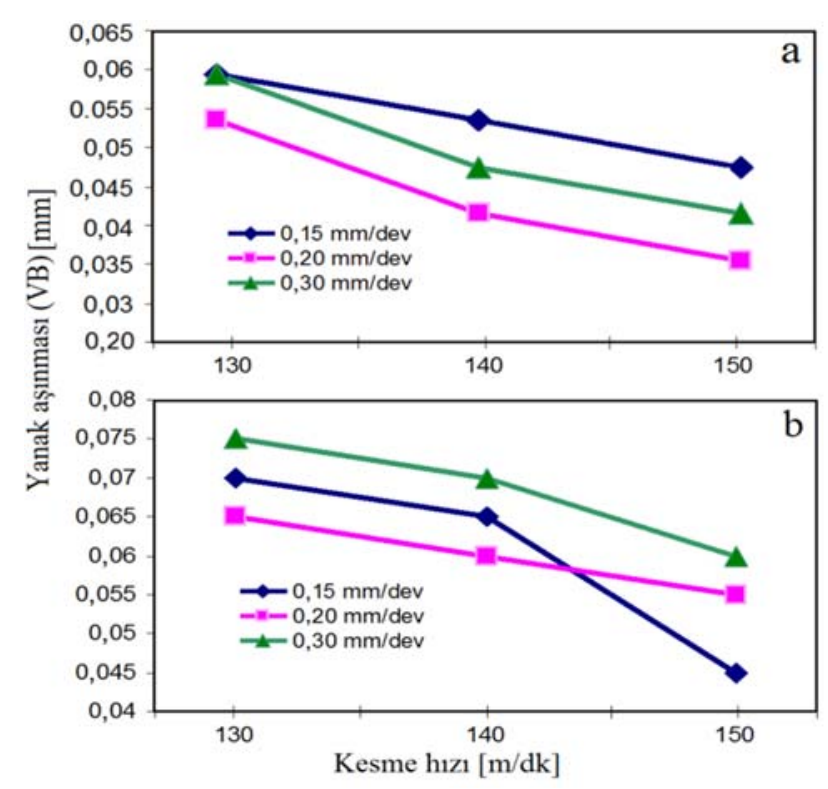

Şekil 2. Kesme hızı ve ilerleme hızının değişiminin yanak aşınmasına etkisi a) IC8250 b) IC9250

(The variation of cutting speed and feed rate effect on flank wear a) IC8250 b) IC9250)

Şekil 3a, Şekil 3b ve Şekil 3c'de 0,20 mm/dev sabit ilerleme hızı altında sırasıyla 130, 140 ve $150 \mathrm{~m} / \mathrm{dk}$ kesme hızlarında oluşan yanak aşınması SEM fotoğrafları IC 9250 tip karbür takma uç için gösterilmiştir. Şekil 4'de ise $10 \mathrm{~m} / \mathrm{dk}$ sabit kesme hızında $0,15,0,20$ ve $0,30 \mathrm{~mm} / \mathrm{dev}$ ilerleme hızlarında oluşan yanak aşınması SEM fotoğrafları gösterilmiştir. Şekil 5'de $0,20 \mathrm{~mm} / \mathrm{dev}$ sabit ilerleme hızı altında 130,140 ve 150 $\mathrm{m} / \mathrm{dk}$ kesme hızlarında oluşan burun aşınma fotoğrafları IC 8250 tip karbür takma uç için gösterilmiştir. 

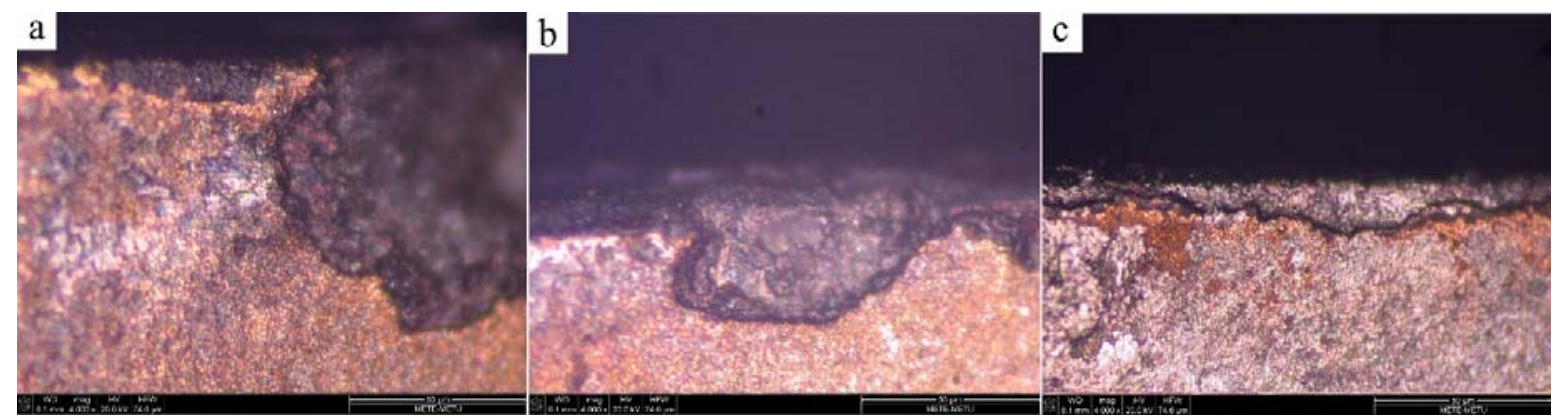

Şekil 3. Sabit 0,20 mm/dev ilerleme hızında sırasıyla a) $130 \mathrm{~m} / \mathrm{dk}$ b) $140 \mathrm{~m} / \mathrm{dk} \mathrm{c)} 150 \mathrm{~m} / \mathrm{dk}$ hızlarında oluşan yanak aşınması SEM görüntüleri (IC9250) (x50 büyütme)

(SEM images of flank wear in constant feed rate of $0,20 \mathrm{~mm} / \mathrm{rev}$ with the cutting speed of a) $130 \mathrm{~m} / \mathrm{min} \mathrm{b}$ ) $140 \mathrm{~m} / \mathrm{min}$ (c) $150 \mathrm{~m} / \mathrm{min}$ respectively (IC9250) (x50 magnification))

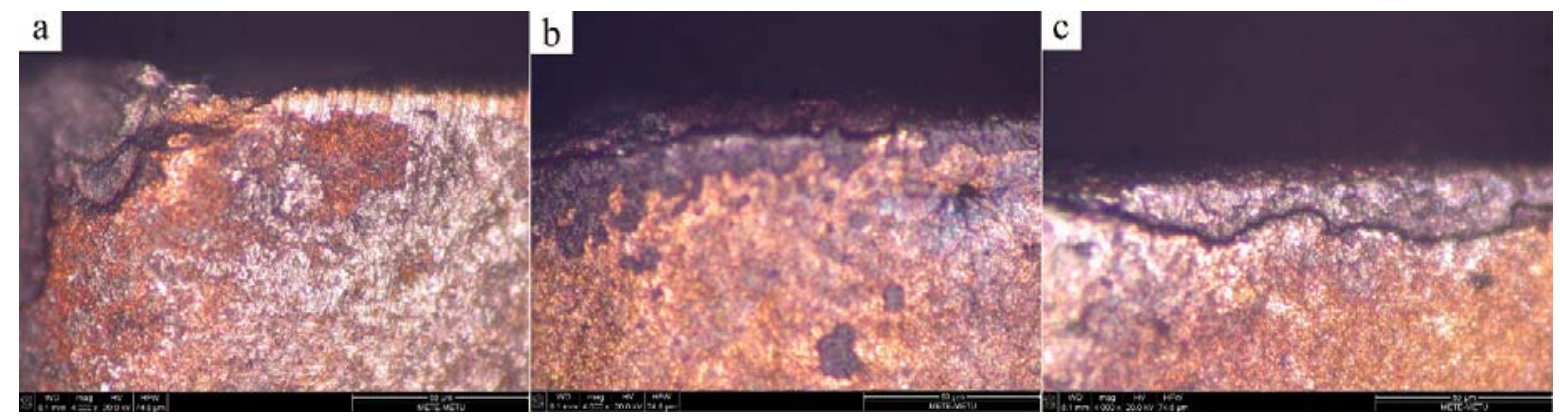

Şekil 4. Sabit $140 \mathrm{~m} / \mathrm{dk}$ kesme hızında, sırasıyla a) $f_{1}=0,15 \mathrm{~mm} / \mathrm{dev}$ b) $f_{2}=0,20 \mathrm{~mm} / \mathrm{dev}$ c) $f_{3}=0,30 \mathrm{~mm} / \mathrm{dev}$ ilerleme hızlarında oluşan yanak aşınması SEM görüntüleri (IC9250) (x50 büyütme)

(SEM images of flank wear in constant cutting speed of $140 \mathrm{~m} / \mathrm{min}$ with the feed rate of a) $0,15 \mathrm{~mm} / \mathrm{rev} \mathrm{b}$ ) $0,20 \mathrm{~mm} / \mathrm{rev} \mathrm{c}$ ) $0,30 \mathrm{~mm} / \mathrm{rev}$ respectively (IC9250) (x50 magnification))

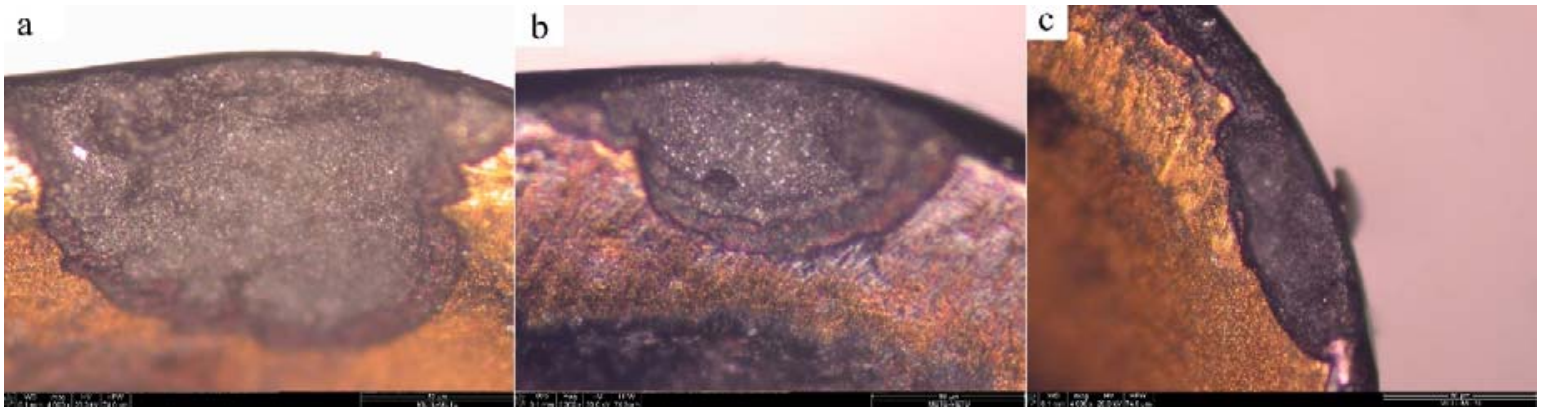

Şekil 5. Sabit $0,20 \mathrm{~mm} / \mathrm{dev}$ ilerleme hızında, sırasıyla a) $130 \mathrm{~m} / \mathrm{dk}$ b) $140 \mathrm{~m} / \mathrm{dk} \mathrm{c}$ ) $150 \mathrm{~m} / \mathrm{dk}$ kesme hızlarında oluşan burun aşınması SEM görüntüleri (IC9250) (x50 büyütme)

(SEM images of nose wear in constant feed rate of $0,20 \mathrm{~mm} / \mathrm{rev}$ with the cutting speed of a) $130 \mathrm{~m} / \mathrm{min} \mathrm{b}$ ) $140 \mathrm{~m} / \mathrm{min} \mathrm{c}$ ) $150 \mathrm{~m} / \mathrm{min}$ respectively (IC9250) (x50 magnification))

3.2. SAE 1030 Dövme Çelik Malzemenin İşlenmesinde Kesme Parametrelerinin Yüzey Pürüzlülüğ̈̈ne Etkisi

(The Effect of Cutting Parameters on Surface Roughness in Machining of SAE 1030 Forged Steel Material)

Yüzey pürüzlülüğü ile kesme parametreleri arasındaki ilişkiyi irdeleyebilmek için iki farklı kesici uç, farklı kesme hızı ve ilerleme hızıyla deney numuneleri işlenmiştir. Daha sonra işlenen numuneler içerdiği parametreler ile işaretlenmiş ve işlenmiş numunelerin yüzey pürüzlülükleri ölçülmüştür. Alınan ölçümler Tablo 3'de gösterilmiştir. En düşük yüzey pürüzlülük değeri $140 \mathrm{~m} / \mathrm{dk}$ kesme hızında 0,15 $\mathrm{mm} / \mathrm{dev}$ ilerleme hızında $2,176 \mu \mathrm{mRa}$ olarak gerçekleşmiştir
(Şekil 6). Kesme hızı arttığında ortalama yüzey pürüzlülük değerinin de arttı̆̆ gözlemlenmiştir.

\subsection{Farklı Kesme Parametrelerinde ve Farklı Zamanlarda Oluşan İşleme Seslerinin Incelenmesi}

(Investigation of the Machining Sound in different Cutting Parameters and at Different Machining Time)

\subsubsection{Güç tayfsal yoğunluğu (Power spectral density PSD)}

Sayısal olarak tanımlı sinyallerin farklı frekans değerlerine göre taşıdığı enerji değerini ya da oranını bulmak kolaydır. Fakat elimizde random bir sinyal varsa işler daha farklı bir 
Tablo 3. Deney numunelerinin yüzey pürüzlülük değerleri (Surface roughness values of test samples)

\begin{tabular}{|c|c|c|c|c|c|c|c|}
\hline \multirow{2}{*}{$\begin{array}{l}\text { Kesici } \\
\text { Takım }\end{array}$} & \multirow{2}{*}{$\begin{array}{l}\text { Kesme Hiz1 } \\
{[\mathrm{m} / \mathrm{dk}]}\end{array}$} & \multirow{2}{*}{$\begin{array}{l}\text { İlerleme } \\
\text { Hizı } \\
{[\mathrm{mm} / \mathrm{dev}]}\end{array}$} & \multicolumn{4}{|c|}{ Yüzey Pürüzlülük Değerleri $(\mu)$} & \multirow{2}{*}{$\begin{array}{l}\text { Ort. Yüzey } \\
\text { pürüzlülüğü } \\
\left(\mu_{o}\right)\end{array}$} \\
\hline & & & 1 & 2 & 3 & 4 & \\
\hline \multirow{9}{*}{ IC 8250} & \multirow{3}{*}{130} & 0,15 & 3,200 & 2,988 & 2,505 & 2,505 & 2,755 \\
\hline & & 0,20 & 3,020 & 2,705 & 2,185 & 2,750 & 2,665 \\
\hline & & 0,30 & 2,525 & 3,295 & 2,095 & 3,130 & 2,761 \\
\hline & \multirow{3}{*}{140} & 0.15 & 2,185 & 2,145 & 2,205 & 2,167 & 2,176 \\
\hline & & 0,20 & 2,305 & 2,187 & 2,550 & 2,675 & 2,429 \\
\hline & & 0,30 & 2,705 & 2,485 & 2,950 & 2,158 & 2,575 \\
\hline & \multirow{3}{*}{150} & 0,15 & 2,505 & 3,100 & 2,575 & 2,705 & 2,721 \\
\hline & & 0,20 & 2,725 & 3,595 & 2,595 & 3,230 & 3,036 \\
\hline & & 0,30 & 2,985 & 2,770 & 2,800 & 3,205 & 2,940 \\
\hline \multirow{9}{*}{ IC 9250} & \multirow{3}{*}{130} & 0,15 & 2,380 & 2,250 & 1,965 & 2,185 & 2,195 \\
\hline & & 0,20 & 2,305 & 2,650 & 2,550 & 2,675 & 2,545 \\
\hline & & 0,30 & 2,705 & 2,485 & 2,550 & 2,458 & 2,550 \\
\hline & \multirow{4}{*}{140} & 0,15 & 2,150 & 2,150 & 2,365 & 2,285 & 2,238 \\
\hline & & 0,20 & 2,405 & 1,975 & 2,550 & 2,458 & 2,347 \\
\hline & & 0,30 & 2,205 & 2,485 & 2,550 & 2,458 & 2,425 \\
\hline & & 0,15 & 2,385 & 2,450 & 2,205 & 2,367 & 2,352 \\
\hline & \multirow[t]{2}{*}{150} & 0,20 & 2,605 & 2,257 & 2,500 & 2,600 & 2,491 \\
\hline & & 0,30 & 2,405 & 2,480 & 2,950 & 2,178 & 2,503 \\
\hline
\end{tabular}

bakış açısıyla ele alınmalıdır. İste bu noktada sinyalin zamana göre davranış biçimini tanımlayabilmek için otokorelasyon fonksiyonu işin içine girer. Power spectral density (PSD) ise otokorelasyon fonksiyonunun fourier transformu alınarak bulunur ve rastgele (random) sinyaller için mevcut sinyalin değişik frekans değerlerine düşen enerji yoğunluğunu gösterir [18].

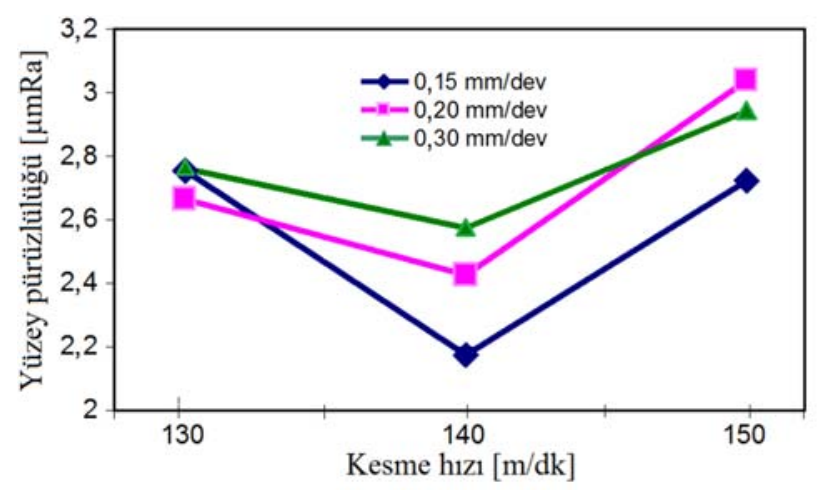

Şekil 6. Kesme hızına bağlı yüzey pürüzlülük değeri değişimi

(The variation of the surface roughness depending on the cutting speed)

\subsection{2. İşleme süresinin ortalama gürültü seviyesi üzerindeki etkisinin incelenmesi}

(Investigation of machining time on average nois level)

Yapılan bu çalışmada farklı kesme parametreleri ve farklı zaman aralıklarında işlenmiş deney numuneleri $\mathrm{CNC}$ tezgâhında işlenirken işleme sesleri bilgisayar ortamına kaydedilmiştir. Elde edilen veriler sadece işleme anındaki veriler olması gerektiği için tezgâhın boşta çalışma sesi ayrıca kaydedilmiştir. Kaydedilen sesler Matlab ${ }^{\circledR}$ programında işlenerek sayısal verilere dönüştürülmüştür. 1082
Elde edilen $x_{\mathrm{i}}(i=1,2, \ldots, N)$ verisinin kareler ortalamasının karekökü (İng. root mean square, rms) Eş. 1'de verilen ifadeyle hesaplanabilir [18], bir başka deyişle $x_{\text {rms }}$ :

$x_{r m s}=\sqrt{\frac{\sum_{i=1}^{N} x_{i}^{2}}{N}}$

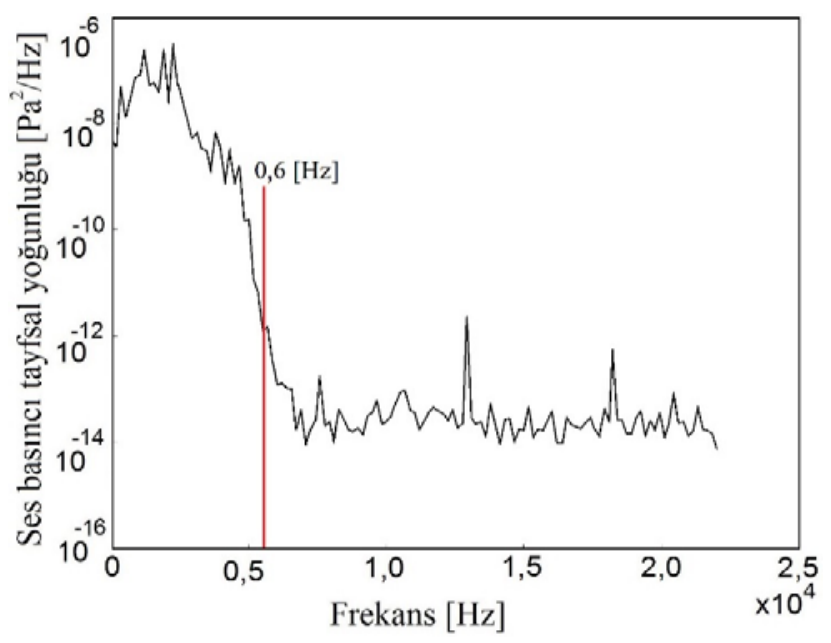

Şekil 7. Tezgâhın boşta çalışma sesinin Güç Tayfsal

Yogunluğu (PSD) (Power spectral density of the unload lathe sound)

Şekil 7'de verilen gürültü tayfsal yoğunluğu (PSD) grafiğine bakıldığında, yaklaşık olarak 0 ilâ $6000 \mathrm{~Hz}$ arasındaki frekans (sıklık) bandının iş parçası ses düzeyi üzerindeki gürültünün etkin olduğu aralık olduğu anlaşılmaktadır. Bu nedenle, iş parçasının işlenmesi sırasında kaydedilen ses basınc1 verileri değerlendirilirken, belirtilen frekans aralığ göz önüne alınmaktadır [18]. Bu aralıkta Ortalama gürültü 
seviyesi (rms değeri) 52,726 dB hesaplanmıştır. Kesme parametreleri incelendikten sonra işleme süresine bağlı ses ölçüm değerlerini $140 \mathrm{~m} / \mathrm{dk}$ kesme hızı $0,20 \mathrm{~mm} / \mathrm{dev}$ ilerleme hızı referans alınarak sabit kesme hızı ve ilerlemede $5, \quad 10,15,20 \mathrm{dk}$ işleme sürelerinde deneyler gerçekleştirilmiştir. Sonuçlar Şekil 8'de gösterildiği gibi en düşük ses basıncı tayfsal yoğunluk seviyesi 5 dakikalık işleme süresinde görülmektedir. İşleme süresi arttıkça ses basıncı tayfsal yoğunluğu değeri de artmaktadır.

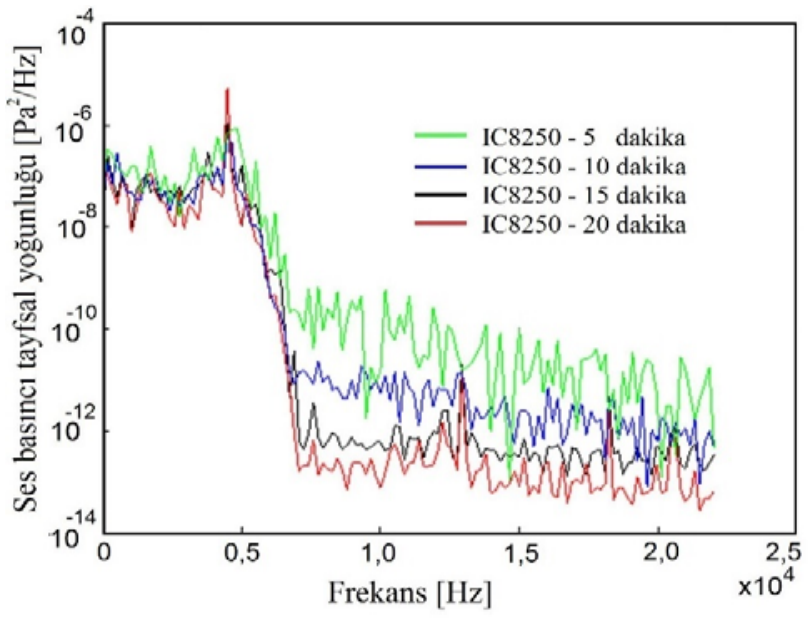

Şekil 8. Farklı işleme süreleri için sabit $140 \mathrm{~m} / \mathrm{dk}$ kesme hızı ve sabit $0,20 \mathrm{~mm} / \mathrm{dev}$ ilerleme hızında işleme yapan IC8250 kesici ucun ses düzeyi tayfsal yoğunluğu (PSD) karşılaştırması

(Comparison of the PSD's of IC8250 tool insert in constant cutting speed of $140 \mathrm{~m} / \mathrm{min}$ and constant feed rate of $0,20 \mathrm{~mm} / \mathrm{rev}$ for different machinig time)

Şekil 9'da farklı tipteki karbür kesici uçların işleme zamanı ses basıncı ilişkisi verilmiştir. Daha sert olan IC9250 kesici ucun aşınma dayanımı daha yüksek olduğu için zaman içerisinde yaydığı ses basıncı nisbeten daha yumuşak uç olan IC8250'ye göre daha düşük çıkmaktadır. Şekil 10'da verilen grafikler incelendiğinde IC9250 kesici takım için, sabit kesme hızı ve ilerleme hızında işleme zamanı arttıkça ses basınç seviyesindeki artış oluşan dalga genliği artışlarından açıkça görülmektedir. Şekil 10a'da $5 \mathrm{dk}$ işleme sonuna doğru akustik emisyon bandı 61,5-62 dB aralığında değişirken 20 $\mathrm{dk}$ işleme sonuna doğru Şekil 10d'de görüldüğü gibi 62,5-63 $\mathrm{dB}$ bir band aralığında değişim göstermektedir. Takım yanak aşınması arttıkça AE sinyal genliği de artış göstermektedir.

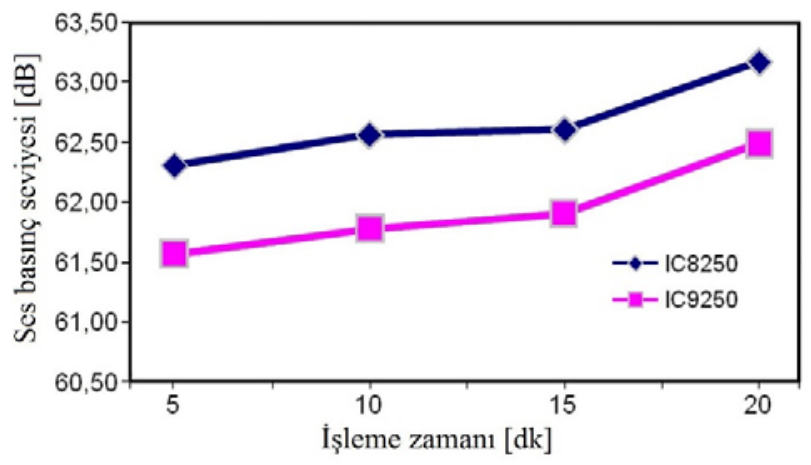

Şekil 9. IC8250 ve IC9250 karbür uçların süreye bağlı ses basınç ölçümleri

(Time dependent sound pressure level measurements of carbide insert i.e. IC8250 and IC9250)

\subsubsection{Kesme parametrelerinin ortalama gürültü seviyesi üzerindeki etkisinin incelenmesi \\ (Investigation of machining parameters on average nois level)}

Deney numunelerinin farklı kesme parametrelerinde işlenmesi sonucunda kaydedilen işleme seslerine bakıldığında kesme hızının artığı noktalarda ses basınç seviyelerinde nisbeten azalma gözlemlenmiştir. İlerleme hızının arttığı noktalarda doğru orantılı olarak ses basınç düzeylerinde belirgin artışlar gözlemlenmiştir. Sırasıyla Şekil 11a'da IC 8250 Şekil 11b'de IC 9250 karbür takma ucu ile işlemenin ses basıncı-kesme/ilerleme hızları ilişkisi verilmiştir.

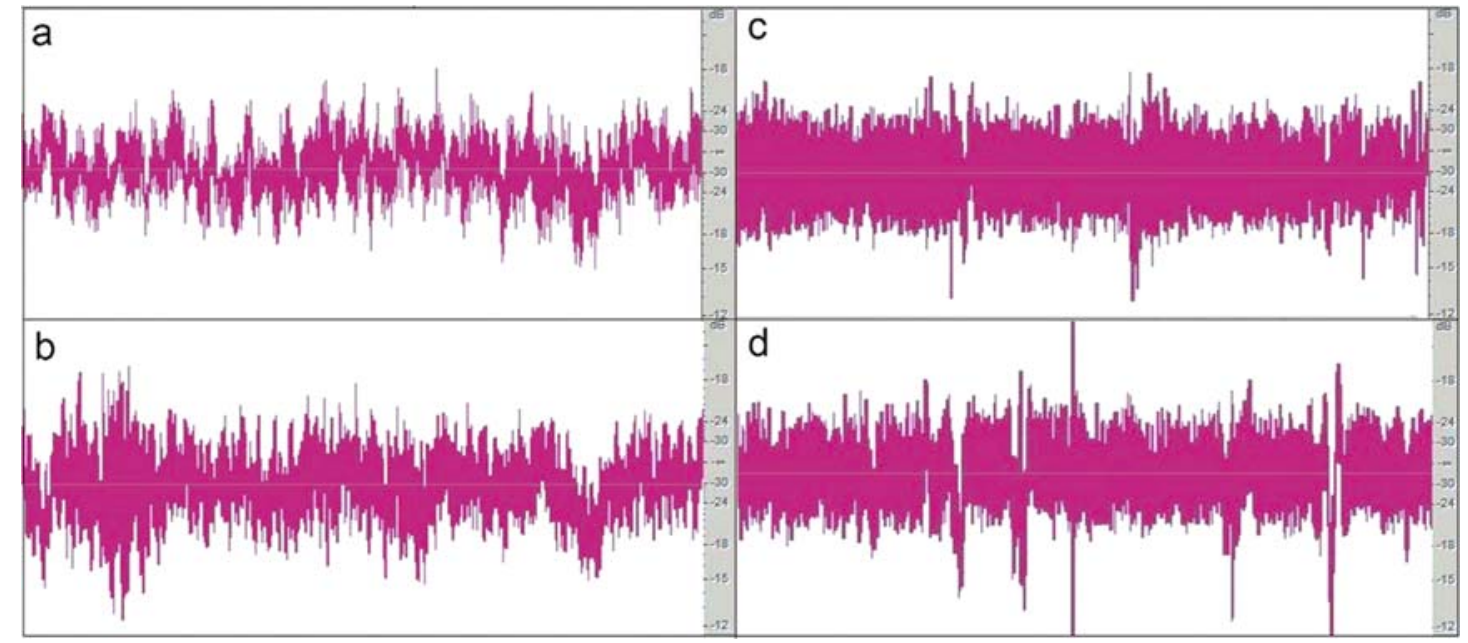

Şekil 10. IC9250 için sabit $140 \mathrm{~m} / \mathrm{dk}$ kesme hızı ve $0,2 \mathrm{~mm} / \mathrm{dev}$ ilerleme hızında a) 5 . dk b) 10. dk c) 15. dk d) 20. dk işleme sürelerinde ölçülen AE sinyalleri [11]

(The measured AE signals at a) $5 . \min$ b) $10 . \min$ c) $15 . \min$ d) 20. min of machining time for IC9250) 


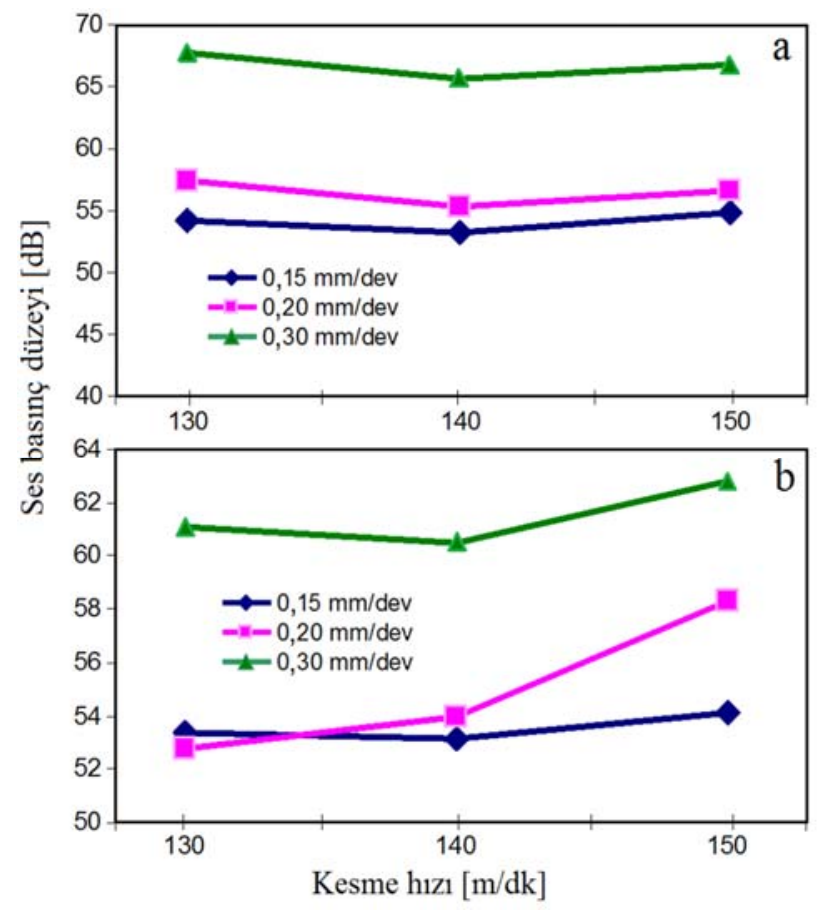

Şekil 11. İki farklı kesme ucunun farklı kesme parametrelerindeki ses basıncı değerleri a) IC8250 b) IC9250

(Sound pressure level values of two different carbide insert a) IC8250 b) IC9250)

Deney numunelerinden elde edilen ses kayıtlarına göre en düşük ses basınç düzeyi $140 \mathrm{~m} / \mathrm{dk}$ kesme hızı ve 0,20 $\mathrm{mm} / \mathrm{dev}$ ilerleme hızında görülmüştür. $\mathrm{Bu}$ nedenle ideal kesme dediğimiz olay bu parametrelerde sağlanmıştır. İşleme seslerinin basınç düzeyi bu değere kadar düşüş gösterirken $150 \mathrm{~m} / \mathrm{dk}$ 'ya çıktığında ise belli bir miktar artış göstermiştir. Kaydedilen seslerin Matlab ortamında sayısal verilere dönüştürülmüş şekli Tablo 4 ‘de verilmiştir.

Tablo 4. Kesici uçların farklı kesme parametrelerine göre ses basınç düzeyleri $(\mathrm{dB})$

(Sound pressure levels $(\mathrm{dB})$ of tool insert vs. different cutting parameters)

\begin{tabular}{lllll}
\hline \multirow{2}{*}{$\begin{array}{l}\text { Kesici } \\
\text { Tak1m }\end{array}$} & \multirow{2}{*}{$\begin{array}{l}\text { İlerleme Hiz1 } \\
{[\mathrm{mm} / \text { devir }]}\end{array}$} & \multicolumn{3}{c}{ Kesme Hiz1 $[\mathrm{m} / \mathrm{dk}]$} \\
\cline { 3 - 5 } & & 130 & 140 & 150 \\
\hline \multirow{2}{*}{ IC 8250 } & 0,15 & 54,1676 & 53,1594 & 54,8895 \\
& 0,20 & 57,4233 & 55,2741 & 56,5566 \\
& 0,30 & 67,7245 & 65,7245 & 66,7977 \\
IC 9250 & 0,15 & 53,3770 & 53,1448 & 54,1241 \\
& 0,20 & 52,7701 & 53,9547 & 58,3251 \\
& 0,30 & 61,1071 & 60,4645 & 62,8290 \\
\hline
\end{tabular}

IC8250 takıma ait ses basıncı tayfsal yoğunluğu 0,15, 0,20 ve $0,30 \mathrm{~mm} / \mathrm{dev}$ ilerleme hızları için sırasıyla, Şekil 12 'de 130 m/dk, Şekil 13'de 140 m/dk ve Şekil 14'de 150 m/dk olarak aşağıda grafiklerde gösterilmiştir. $\mathrm{Bu}$ grafiklerden görüleceği üzere sabit teğetsel kesme hızı altında ilerleme hızı arttıkça yayılan sesin gücü artmaktadır. Bu da bize takımın daha fazla aşındığını göstermektedir. 1084

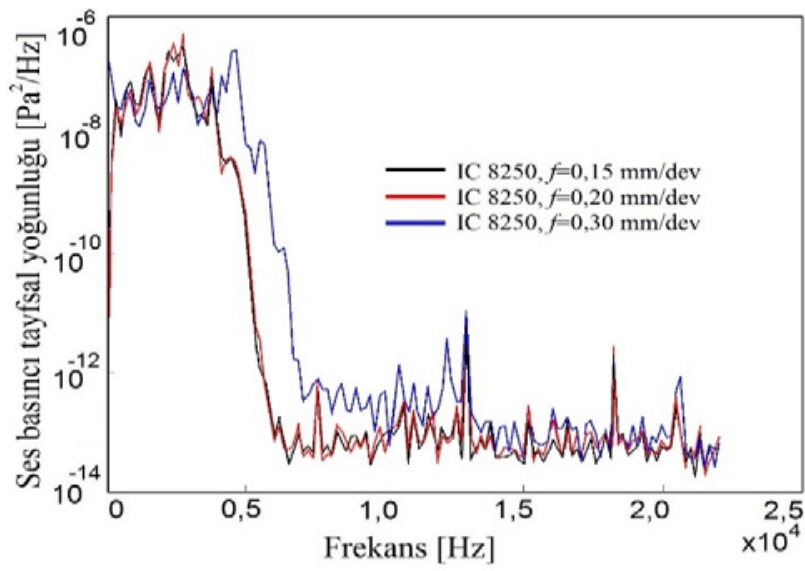

Şekil 12. IC 8250 Kesici uç için sabit 130 m/dk kesme hızı ve farklı ilerleme hızlarındaki gürültü seviyesinin rms değerleri (The rms values of nois level in constant $130 \mathrm{~m} / \mathrm{dk}$ cutting speed and different feed rates for IC 8250 tool insert)

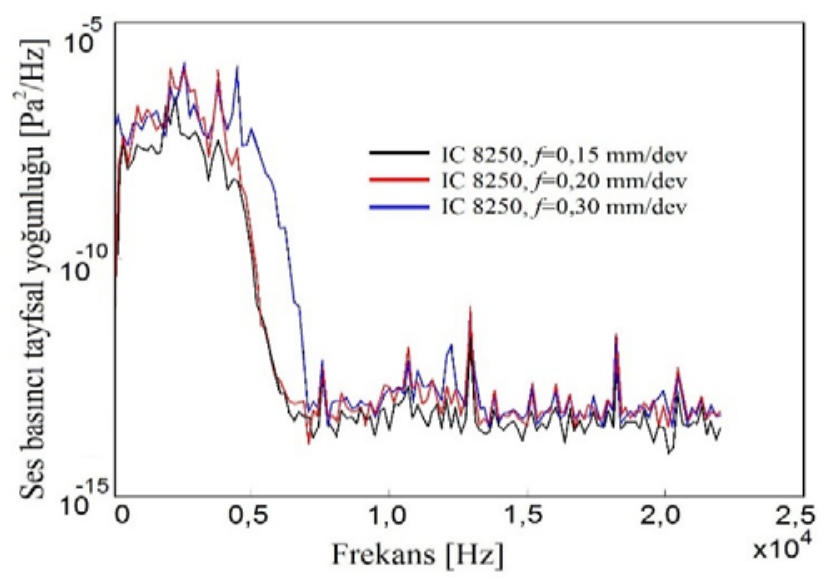

Şekil 13. IC 8250 Kesici uç icin sabit 140 m/dk kesme hızı ve farklı ilerleme hızlarındaki gürültü seviyesinin rms değerleri

(The rms values of nois level in constant $140 \mathrm{~m} / \mathrm{min}$ cutting speed and different feed rates for IC 8250 tool insert)

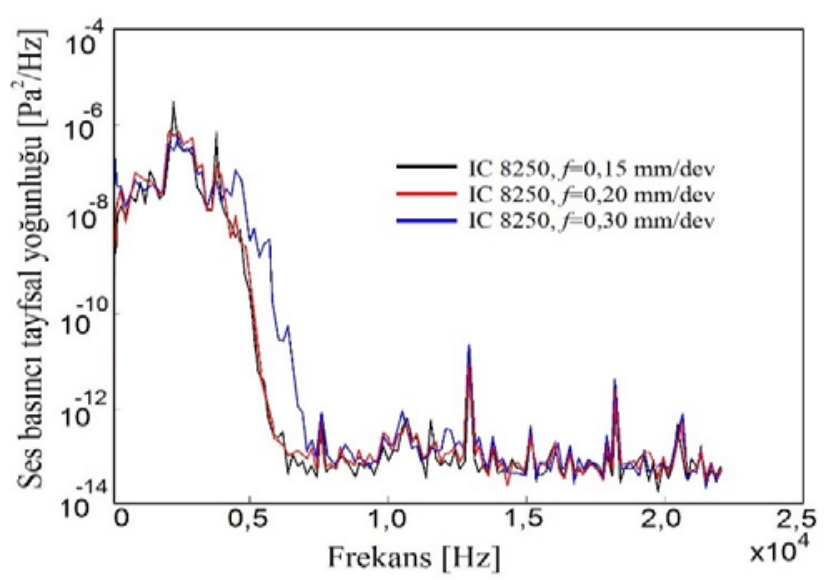

Şekil 14. IC 8250 Kesici uç için sabit 150 m/dk kesme hızı ve farklı ilerleme hızlarındaki gürültü seviyesinin rms değerleri

(The rms values of nois level in $150 \mathrm{~m} / \mathrm{min}$ constant cutting speed and different feed rates for IC 8250 tool insert) 
Tezgâhın kesme yaparken ölçülen AE değerleriyle boşta çalışırken çıkan AE değerlerini karşılaştırdı̆̆ımızda ortaya çıkan fark Şekil 15'de verilen grafikte açıkça görülmektedir. Tezgâh kesme yaparken daha yüksek seviyede ses basıncı yaymaktadır. Şekil 15, Şekil 16 ve Şekil 17’de değişik kesme şartlarında $\mathrm{dB}$ cinsinden ses basıncı değerlerinin frekansa bağlı değişimleri verilmiştir.

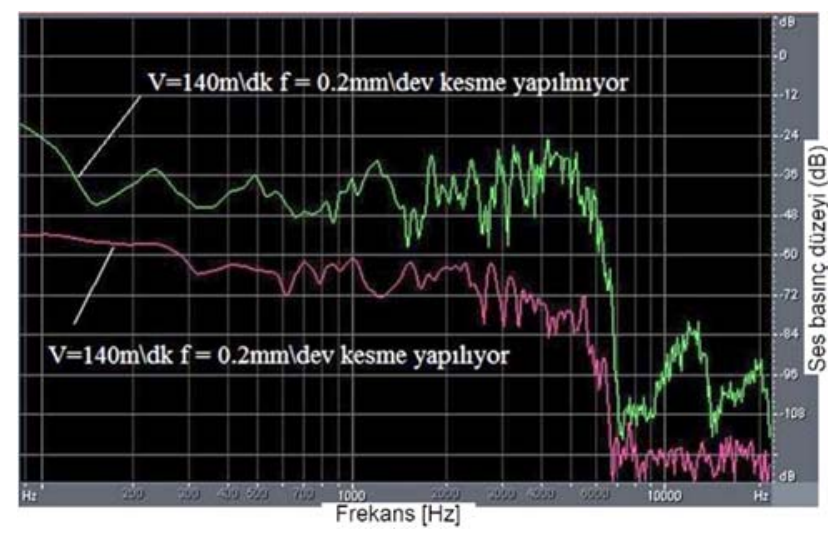

Şekil 15. Aynı kesme parametresinde tezgâhın talaş kaldırarak ve talaş kaldırmadan kaydedilmiş ses basınç seviyesi

(The recorded sound pressure level of load and unload lathe for the same cutting parameters)

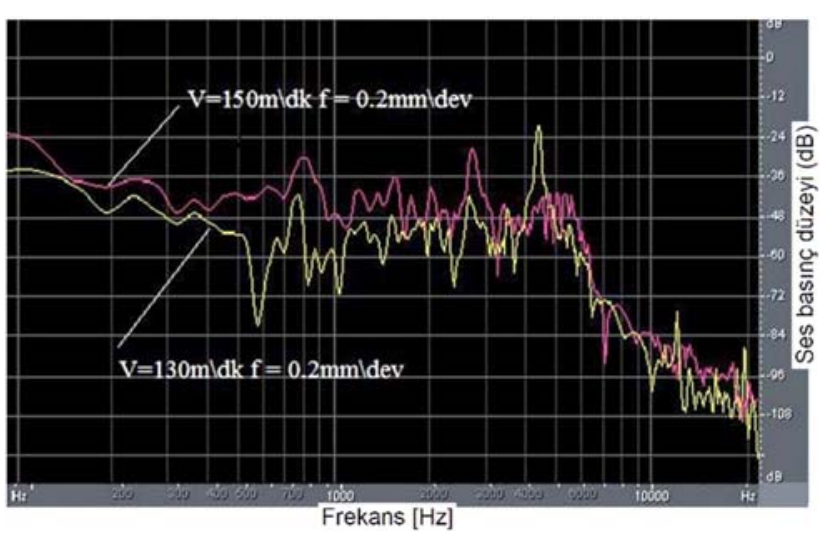

Şekil 16. Kesme hızı ile ses basınç seviyesi arasındaki ilişki (The relationship between the cutting speed and the sound pressure level)

Grafik verileri incelendiğinde, kesme hızlarının artmasıyla işleme seslerinin basınç seviyelerinde azalma gözlemlenmiştir. $130 \mathrm{~m} / \mathrm{dk}$ kesme hızından $140 \mathrm{~m} / \mathrm{dk}$ ' ya çıktığında basınç düzeyi örnek olarak alınan $0,20 \mathrm{~mm} / \mathrm{dev}$ sabit ilerleme hızında 57,40 dB den 55,20 dB'e düşmüştür. Kesme hızı $V=150 \mathrm{~m} / \mathrm{dk}$ ' ya çıktığında ise ses basınç seviyesi $56,50 \mathrm{~dB}$ değerine doğru bir miktar artış göstermiştir (Şekil 16).

\subsubsection{Yüzey pürüzlülüğü ile ses basınç düzeyi arasındaki ilişki}

(The relationship between the surface roughness and sound pressure level)

Bu kısımda ölçülen ses basınç düzeyi ile numune yüzey pürüzlük değerleri karşılaştırılarak aralarındaki ilişki incelenmiştir. Kesme hızı 130 m/dk' dan 140 m/dk'ya artırıldığında ortalama yüzey pürüzlülük değeri düşerken kesme hızı 150 m/dk'ya çıktıktan sonra deney numunesi yüzeyinde yer yer bozulmaların arttığı ve buna bağlı olarak yüzey pürüzlük değerlerinde artışlar olduğu gözlenmiştir. İlerleme hızının yüzey pürüzlülügüne etkisiyle ilgili incelemelerde ise en uygun kesme hızı değeri olan $140 \mathrm{~m} / \mathrm{dk}$ sabit hız altında deneyler gerçekleştirilmiştir. $0,15 \mathrm{~mm} / \mathrm{dev}$ ve $0,20 \mathrm{~mm} / \mathrm{dev}$ ilerleme hızlarında ortalama yüzey pürüzlük değeri düşük değerde iken $0,30 \mathrm{~mm} /$ dev'e çıktığında yüzey pürüzlülüğü ani artış göstermiştir AE değerlerinin ilerleme hızlarının artışıyla arttığı gözlenmiştir. Ses basınç düzeyinin artışına paralel olarak yüzey pürüzlülük değerlerinde de artışlar olduğu tespit edilmiştir (Şekil 17).

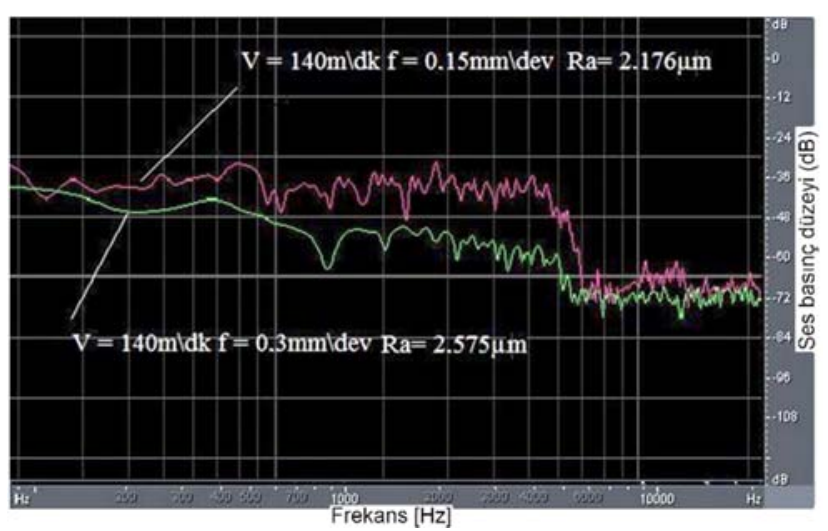

Şekil 17. İlerleme hızı ile ses basınç seviyesi ve yüzey pürüzlülüğü arasındaki ilişki

(The relationship between the feed rate, the sound pressure level and the surface roughness)

Ses basınç düzeyi ile yüzey pürüzlülük değerleri arasındaki ilişki, sabit $140 \mathrm{~m} / \mathrm{dk}$ kesme hızında ve $0,15,0,20$ ve 0,30 $\mathrm{mm} / \mathrm{dev}$ ilerleme hızları için Şekil 18' de gösterilmiştir. Buna göre sabit kesme hızında ilerlemeye bağlı olarak en düşük yüzey pürüzlülük değeri $2,176 \mu \mathrm{mRa}$ ve ses basınç düzeyi $\sim 53 \mathrm{~dB}$ olarak $0,15 \mathrm{~mm} /$ dev'de (Şekil 18a) elde edilmiştir. Şekil $18 b$ 'de $0,20 \mathrm{~mm} / \mathrm{dev}$ ve Şekil $18 \mathrm{c}$ 'de $0,30 \mathrm{~mm} / \mathrm{dev}$ sabit ilerleme altında yüzey pürüzlülüğü-ses basınç seviyesi ilişkileri gösterilmiştir.

\section{TAKIM AŞINMASI MODELİ (TOOL WEAR MODEL)}

$\mathrm{Bu}$ bölümde, yapılan deneyler sonucunda elde edilen verilerden yola çıkarak en iyi kesme parametreleri; $V=140$ $\mathrm{m} / \mathrm{dk}$ kesme hızı, $f=0,20 \mathrm{~mm} / \mathrm{dev}$ ilerleme hızı referans alınmıştır. Bu değerler kesici ucun katalog değerleri arasında da en uygun değer olarak yer almaktadır. $V=140 \mathrm{~m} / \mathrm{dk}$ kesme hızı, $f=0,20 \mathrm{~mm} / \mathrm{dev}$ ilerleme hızı sabit tutularak farklı zaman aralıklarında hesaplanan ses basınç seviyesi, yanak aşınması ve yüzey pürüzlülüğü deneysel ve modellerden hesaplanan değerler olarak bir arada Tablo 5 'te verilmiştir. Tablo 5'ten elde edilen veriler ışığında yanak aşınmasını işleme zamanına bağlayan bir model oluşturulmuştur. Bahsedilen modelleme çalışması iki aşamada gerçekleştirilmiş olup, ilk aşamada ses basıncı işlem süresinin fonksiyonu olarak ifade edilmiş, ikinci aşamada ise 
bir önceki safhada hesaplanan ses basınç seviyesi değeri kullanılarak yanak aşınmasını veren ifade, ölçüm verilerini gerçeğe en yakın şekilde ifade etmek üzere doğrusal olmayan bir fonksiyon olarak elde edilmiştir. Böylelikle, elde süre bilgisinin mevcut olması durumunda belirtilen her iki ifade kullanılarak ortalama yanak aşınması yaklaşık olarak \%99,5'e varan bir doğrulukla hesaplanabilmektedir.

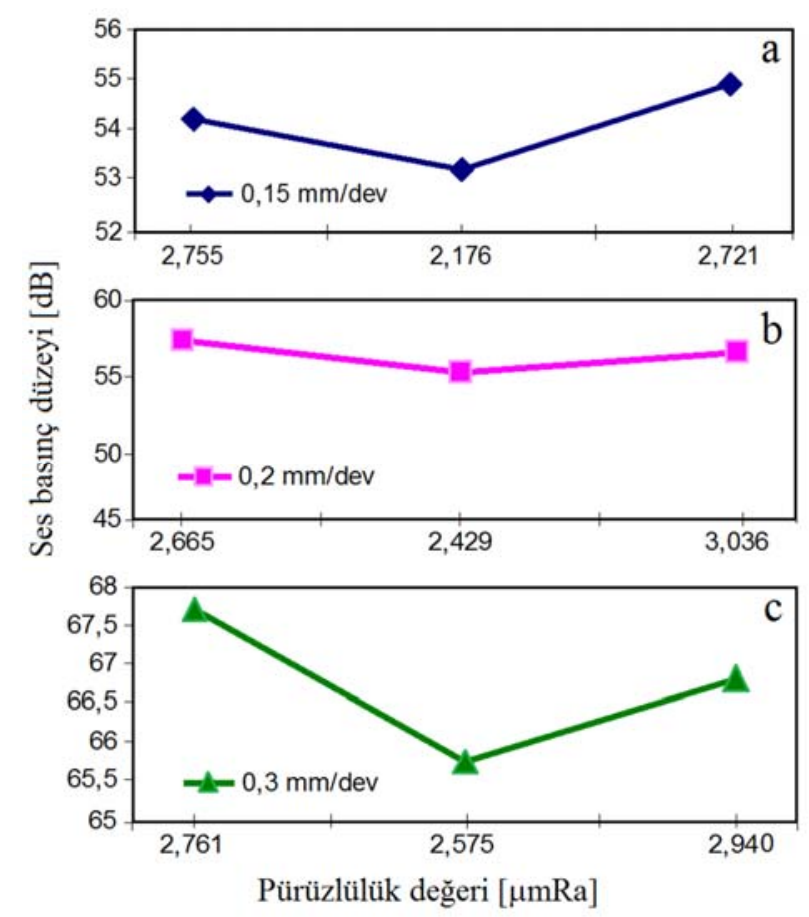

Şekil 18. $140 \mathrm{~m} / \mathrm{dk}$ sabit kesme hızında ölçülen yüzey pürüzlülükleri ve ses basınç düzeyleri karşılaştırılması a) $0,15 \mathrm{~mm} / \mathrm{dev}$ b) $0,20 \mathrm{~mm} / \mathrm{dev}$ c) $0,30 \mathrm{~mm} / \mathrm{dev}$ ilerlem hızı için

(The comparison of surface roughness and sound pressure levels in 140 $\mathrm{m} / \mathrm{min}$ constant cutting speed for a) $0.15 \mathrm{~mm} / \mathrm{dev}$ b) $0.20 \mathrm{~mm} / \mathrm{dev}$ c) 0.30 $\mathrm{mm} / \mathrm{rev}$ fees rate)
Öteyandan, uygun şekilde seçilmiş bir ses kayıt cihazı yardımıyla alınan kesme gürültüsü verilerinin işlenmesi sonunda bulunan ses basınç seviyesi büyüklükleri kullanılarak, ilk ifadeye gereksinim duyulmadan doğrudan modelin ikinci eşitliğinden yanak aşınması değerleri yine yüksek korelasyonla hesaplanabilmektedir. Yapılan deneyde iki farklı kesici uçla sabit kesme hızı ve ilerlemede 5. ile 20. dakika arasındaki aşınmalar ses basınç düzeyine göre belirlenmiştir. IC8250 ve IC9250 takımları için deneysel verilerle modelden hesaplanan değerler Tablo 6' da gösterilmiştir. Aşağıda Eş. 2 ve Eş. 4 numaralı eşitliklerde yer alan " $S(t)$ " ifadesi $[\mathrm{dB}]$ olarak ses basınç seviyesini, " $t$ " dakika olarak zamanı ve Eş. 3 ve Eş. 5 numaralı eşitliklerde verilen " $W(s)$ " ise ses basıncı cinsinden [mm] olarak aşınma miktarını göstermektedir.

IC 8250 tipi kesici uç için zamana bağlı model formülasyonu:

$$
\begin{aligned}
& S(t)=-0,004072 t^{3}+0,1578 t^{2}-1,804 t+67,89 \\
& {[\mathrm{~dB}](t: \text { dakika })} \\
& W(s)=-0,2068-0,4157 \cos (5,893 s)-0,2981 \sin (5,893 s) \\
& {[\mathrm{mm}](s: \mathrm{dB})}
\end{aligned}
$$

IC 9250 tipi kesici uç için model formülasyonu:

$$
\begin{aligned}
& S(t)=0,000712 t^{3}-0,02296 t^{2}+0,262 t+60,74 \\
& {[\mathrm{~dB}](t \text { : dakika })} \\
& W(s)=0,1377+0,07063 \cos (4,133 s)-0,004 \sin (4,133 s) \\
& {[\mathrm{mm}](\mathrm{s}: \mathrm{dB})} \\
& \text { olarak türetilebilir. }
\end{aligned}
$$

Tablo 5. $140 \mathrm{~m} / \mathrm{dk}$ kesme ve $0,20 \mathrm{~mm} / \mathrm{dev}$ ilerleme hızlarında farklı zaman aralıklarında ölçülen takım aşınması yüzey pürüzlülüğü ve bunlara karşılık gelen ses basıncı değerleri (Measured tool wear surface roughness and corresponding sound pressure values for $140 \mathrm{~m} / \mathrm{min}$ cutting speed and $0.20 \mathrm{~mm} / \mathrm{rev}$ feed rate at different time intervals)

\begin{tabular}{lllll}
\hline Kesici takım & Süre [dk] & $\begin{array}{l}\text { Ses basıç seviyesi } \\
{[\mathrm{dB}]}\end{array}$ & $\begin{array}{l}\text { Yanak aşınmasi } \\
{[\mathrm{VB} / \mathrm{mm}]}\end{array}$ & $\begin{array}{l}\text { Yüzey pürüzlülük } \\
\text { değerleri }[\mu \mathrm{mRa}]\end{array}$ \\
\hline \multirow{2}{*}{ IC 8250} & 5 & 62,309 & 0,074 & 2,65 \\
& 10 & 62,564 & 0,110 & 2,75 \\
& 15 & 62,603 & 0,170 & 2,74 \\
IC 9250 & 20 & 63,172 & 0,210 & 3,79 \\
& 10 & 61,567 & 0,067 & 1,90 \\
& 15 & 61,778 & 0,095 & 2,24 \\
& 20 & 61,909 & 0,130 & 2,49 \\
\hline
\end{tabular}


Tablo 6. $140 \mathrm{~m} / \mathrm{dk}$ kesme hızı ve $0,20 \mathrm{~mm} / \mathrm{dev}$ ilerleme hızında farklı zaman aralıklarındaki deney verileri ve hesaplanan değerler (The experimental and calculated values for $140 \mathrm{~m} / \mathrm{min}$ cutting speed and $0,20 \mathrm{~mm} / \mathrm{rev}$ feed rate at different time intervals)

\begin{tabular}{lllllll}
\hline $\begin{array}{l}\text { Kesici } \\
\text { Takım }\end{array}$ & Süre [dk] & $\begin{array}{l}\text { Ses Basıç } \\
\text { Seviyesi }[\mathrm{dB}]\end{array}$ & $\begin{array}{l}\text { Yanak } \\
\text { Aşınmas1 } \\
{[\mathrm{VB} / \mathrm{mm}]}\end{array}$ & $\begin{array}{l}\text { Yüzey } \\
\text { Pürüzlülük } \\
\text { Değerleri } \\
{[\mu \mathrm{mRa}]}\end{array}$ & $\begin{array}{l}\text { Hesaplanan } \\
\text { Ses Basıç } \\
\text { Seviyesi }[\mathrm{dB}]\end{array}$ & $\begin{array}{l}\text { Hesaplanan } \\
\text { Yanak } \\
\text { Aşınmas1 } \\
{[\mathrm{VB} / \mathrm{mm}]}\end{array}$ \\
\hline & 5 & 62,309 & 0,074 & 2,65 & 62,306 & 0,069 \\
IC 8250 & 10 & 62,564 & 0,110 & 2,75 & 62,558 & 0,115 \\
& 15 & 62,603 & 0,170 & 2,74 & 62,592 & 0,174 \\
& 20 & 63,172 & 0,210 & 3,79 & 63,354 & 0,206 \\
\hline \multirow{2}{*}{ IC 9250 } & 5 & 61,567 & 0,067 & 1,90 & 61,565 & 0,067 \\
& 10 & 61,778 & 0,095 & 2,24 & 61,776 & 0,095 \\
& 15 & 61,909 & 0,130 & 2,49 & 61,907 & 0,130 \\
\hline
\end{tabular}

Yüzey pürüzlülüğü ile ses basıncı seviyesi arasındaki çapraz iliş̧inin hem deneysel hem de modelden hesaplanmış değerleri her iki farklı takım ucu için Şekil 19'da gösterilmiştir. Yüzey pürüzlülüğü arttıça takım ucu aşınmasından kaynaklı olarak açığa çıkan akustik emisyon değerlerindeki artış açıkça görülmektedir. Benzer sonuçlar Bhuiyan vd. [13] çalışmalarında da belirtilmiştir.

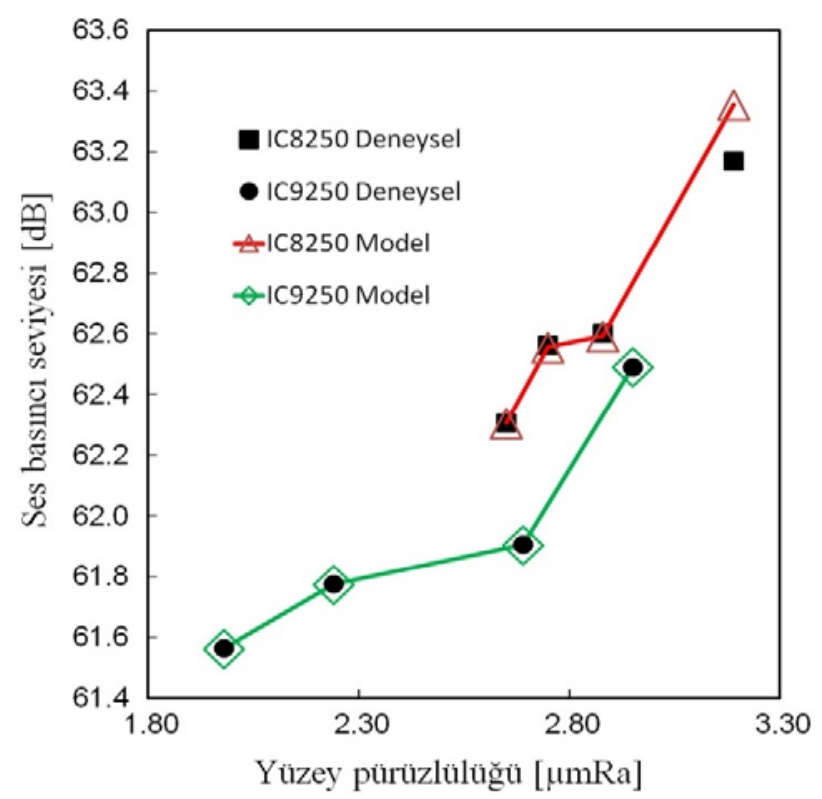

Şekil 19. a) IC 850 takım ucu b) IC950 takım ucu için ses basıncı düzeyinin yüzey pürüzlülüğüyle değișimi

(The variation of surface roughness and sound pressure levels for a) IC850 tool insert b) IC950 tool insert)

\section{SONUÇLAR (CONCLUSIONS)}

Deney numunelerinin işlenmesi esnasında devir, kesme hızı ve ilerleme miktarının farklılığına bağlı olarak işleme ses basınç düzeyleri değişmektedir. Kesme hızının artmasıyla ses basınç düzeyi azalırken, ilerleme hızının artmasıyla ses basınç düzeyi (gürültü) artmaktadır. Kesici takım ucunun 20. dakikadaki kesme değerleri, çıkan talaş boyutları ve kaydedilen ses basınç düzeyi 5. dakikadaki değerlere göre daha yüksek çıkmaktadır. Buna göre işleme zamanı artıkça kaydedilen ses basınç seviyelerindeki artış, kesme parametrelerini klasik metotların dışında işleme seslerinin basınç düzeylerini karşılaştırarak da belirleyebileceğimizi göstermiştir. SAE 1030 Dövme çeliklerde kesme parametrelerinin torna tezgâhında işleme esnasındaki sese dayalı olarak tespitini amaçlayan bu çalışmada somut olarak elde edilen sonuçları özetleyecek olursak; $140 \mathrm{~m} / \mathrm{dk}$ kesme hızında $0,20 \mathrm{~mm} / \mathrm{dev}$ ilerleme hızında en az yanak aşınması olduğu görülmüştür. Kesme hızının artması yanak aşınmasını azaltmıştır. Yapılan ölçümler sonucu en düşük ortalama yüzey pürüzlülük (Ra) değeri $0,15 \mathrm{~mm} / \mathrm{dev}$ ilerleme ve $140 \mathrm{~m} / \mathrm{dk}$ kesme hızında gerçekleşmiştir. Kesme hızı arttığında ortalama yüzey pürüzlülük değerinin de $\operatorname{arttığ~}$ gözlenmiştir. Sabit $0,20 \mathrm{~mm} / \mathrm{dev}$ ilerlemede hızı altında, kesme hızı 130 m/dk'dan 150 m/dk'ya çıkıldığı zaman burun aşınması 0,156 mm'den 0,122 mm'ye kadar azaldı̆̆ 1 tespit edilmiştir. Tezgâhın boş çalışma durumunda ortalama gürültü seviyesi (rms olarak) 52,72 dB hesaplanmıştır. 130 $\mathrm{m} / \mathrm{dk}$ kesme hızından $140 \mathrm{~m} / \mathrm{dk}$ 'ya çıktığında basınç düzeyi örnek olarak alınan $0,20 \mathrm{~mm} / \mathrm{dev}$ sabit ilerleme hizında 57,40 dB'den 55,20 dB'e düşmüştür. Kesme hızı 150 $\mathrm{m} / \mathrm{dk}$ 'ya çıktığında ise ses basınç seviyesi $56,50 \mathrm{~dB}$ seviyesinde bir miktar artış göstermiştir. Kesme hızı değeri $130 \mathrm{~m} / \mathrm{dk}^{\prime}$ dan $140 \mathrm{~m} / \mathrm{dk}$ 'ya artırıldı̆̆ında ortalama yüzey pürüzlülügü sabit ilerlemede $(f=0,20 \mathrm{~mm} / \mathrm{dev})$ sirasiyla $2,665 \mu \mathrm{m}$ ve $2,429 \mu \mathrm{m}$ olarak azalmıs, kesme hızı 150 m/dk'ya çıkarıldığında ise yüzey pürüzlük değeri 3,036 $\mu$ m'ye bir artış göstermiştir. Kesme hızı daha da arttırıldığında deney numunesi yüzeyinde yer yer bozulmaların meydana geldiği gözlemlenmiştir. İdeal kesme parametreleri $140 \mathrm{~m} / \mathrm{dk} 0,20 \mathrm{~mm} / \mathrm{dev}$ olarak bulunmuştur. Bulunan bu değerler kesici takım ucunun katalog değerleriyle uyuşmaktadır [19]. Takım aşınması arttıkça işlenen parçaların yüzey pürüzlülüğünün arttığı bunun sonucu olarak ortama yayılan ses basıncı seviyesinin arttı̆̆ görülmüştür.

Yapılan çalışmalar, SAE 1030 dövme çelik malzemenin tornalama işleminde, ses basınç seviyesiyle kesme 
parametreleri arasındaki ilişkinin klasik metotlarla bulunan değerlerle örtüştüğünü göstermiştir. Belirlenen ideal kesme sesi ile imalat sırasında oluşan işleme sesleri karşılaştırılarak, seri üretim sırasında çok daha düşük maliyetle, takım aşınması ve buna bağlı yüzey pürüzlülüğünün izlenebileceği ve kontrol altına alınabileceği görülmüştür.

\section{SIMGELER (SYMBOLS)}

$\begin{array}{ll}f & \text { İlerleme hızı } \\ \mu & \text { Yüzey pürüzlülük değeri } \\ \mu_{o} & \text { Ortalama yüzey pürüzlülük değeri } \\ N & \text { Ölçüm adedi } \\ s & \text { Ses basıncı seviyesi [dB] } \\ t & \text { İşleme süresi } \\ S(t) & \text { Ses basıncı seviyesinin zamana bağlı fonksiyonu } \\ V & \text { Kesme hızı } \\ x_{i} & \text { Ölçülen ses basıncı değeri } \\ W(t) & \text { Aşınmanın zamana bağlı fonksiyonu }\end{array}$

\section{Kisaltmalar (Abbreviations)}

$\begin{array}{ll}\text { AE } & \text { Akustik emisyon } \\ \text { CNC } & \text { Bilgisayarla sayısal denetimli takım tezgâhı } \\ \text { PSD } & \text { Güç tayfsal yoğunluğu } \\ \text { RMS } & \text { Kareler ortalamasının karekökü } \\ \text { SAE } & \text { Otomotiv mühendisleri derneği } \\ \text { VB } & \text { Yanak aşınması }\end{array}$

\section{KAYNAKLAR (REFERENCES)}

1. Işı1k Y., Çakır M.C., A real-time end of tool life detection system for HSS tools in turning operations, Uludağ Üniversitesi Mühendislik-Mimarlık Fakültesi Dergisi, 7 (1), 211-219, 2002.

2. Taşlıyan A., Acarer M., Şeker U., Gökkaya H., Demir B., The effect of cutting parameters on cutting force during the processing of Inconel 718 super alloy, Journal of the Faculty of Engineering and Architecture of Gazi University, 22 (1), 1-5, 2007.

3. Kaçal A., Yıldırım F., Determining the effects of CBN cutting insert's cutting performance on surface roughness and tool wear at turning of PMD 23 steel, Journal of the Faculty of Engineering and Architecture of Gazi University, 31 (1), 181-189, 2016.

4. Altın A., Optimization of turning machinig parameters in inconel 600 super alloy, Journal of the Faculty of Engineering and Architecture of Gazi University, 28 (4), 677-684, 2013.

5. Taga Ö., Kıral Z., Yaman K., Determination of cutting parameters in end milling operation based on the optical surface roughness measurement, International Journal of Precision Engineering and Manufacturing, 17 (5), 579-589, 2016.
6. Wang B., Zhanquiang L., Acoustic emission signal analysis during chip formation process in high speed machining of 7050-T7451 aluminum alloy and Inconel 718 superalloy, Journal of Manufacturing Processes, 27, 114-125, 2017.

7. Li X., Acoustic emission method for tool wear monitoring during turning, International Journal of Machine Tools and Manufacture, 42 (2), 157-165, 2002.

8. Choi D., Kwon W.T., Chu C.N., Real-time monitoring of tool fracture in turning using sensor fusion, International Journal of Advanced Manufacturing Technology, 15 (5), 305-310, 1999.

9. Deiab I., Assaleh K., Hammada F., On modeling of tool wear using sensor fusion and polynomial classifiers, Journal Materials Processing Technology, 23 (5), 1719 1729, 2009.

10. Bhuiyan M.S.H., Choudhury I.A., Nukman Y., An innovative approach to monitor the chip formation effect on tool state using acoustic emission in turning, International Journal of Machine Tools and Manufacture, 58, 19-28, 2012.

11. Başaltın M., Yaman K., Tool flank wear analysis by acoustic emission (AE) method in turning operation, The First International Mediterranean Science and Engineering Congress, Çukurova University, AdanaTURKEY, 146-153 (ID:65), October 26-28, 2016.

12. Downey J., O'leary P., Raghavendra R., Comparison and analysis of audible sound energy emissions during single point machining of HSTS with PVD TiCN cutter insert across full tool life, Wear, 313 (1-2), 53-62, 2014.

13. Bhuiyan M.S.H., Choudhury I.A., Dahari M., Monitoring the tool wear, surface roughness and chip formation occurrences using multiple sensors in turning, Journal of Manufacturing Systems, 33 (4), 476-487, 2014.

14. Bhuiyan M.S.H., Choudhury I.A., Dahari M., Nukman Y., Dawal S.Z., Application of acoustic emission sensor to investigate the frequency of tool wear and plastic deformation in tool condition monitoring, Measurement, 92, 208-217, 2017.

15. Maia L.H.A., Abrao A.M., Vasconcelos W.L., Sales W.F., Machado A.R., A new approach for detection of wear mechanisms and determination of tool life in turning using acoustic emission, Tribology International, 92, 519-532, 2015.

16. Neslusan M., Micieta B., Micietova A., Cillikova M., Mrkvica I., Detection of tool breakage during hard turning through acoustic emission at low removal rates, Measurement, 70, 1-13, 2015.

17. TS 10329, Torna Kalemleri-Ömür Deneyi, Tool life testing with single-points turning tools, 1992.

18. Matlab online manual. https://uk.mathworks.com. Yayın yılı 2009.

19. ISCAR kesici uç ve Takım tutucu kataloğu. http://www.iscar.com.tr/.Yayın yıl1 2009. 